\title{
EFFECT OF THERMOCYCLING ON REPAIRED ZIRCONIA CERAMIC RESTORATIONS USING DIFFERENT BONDING AGENTS
}

\author{
Shaimaa Ahmed. Abo El-Farag * and Noha Abdel Mawla El-Wassefy **
}

\begin{abstract}
Statement of the Problem: The clinical success of zirconia intra-oral repair depends on the strength of the bond between the zirconia core and veneering composite.

Purpose: In the present study, the effect of aging on the shear bond strength of zirconia ceramic and nanohybrid composite resin as a repair material was evaluated using different bonding agents.

Materials and Method: Fifty six plates of zirconia ceramic $(10 \mathrm{~mm} \times 2 \mathrm{~mm})$ were prepared by $\mathrm{CAD} / \mathrm{CAM}$. All discs were air-abraded using $50 \mu \mathrm{m} \mathrm{Al}_{2} \mathrm{O}_{3}$ particles at 2 bar pressure for $10 \mathrm{~s}$, then divided into two equal groups $\mathrm{A}$ and $\mathrm{B}(\mathrm{n}=28)$ according to exposure to thermocycling. Each group was subdivided into four equal subgroups $(\mathrm{n}=7)$ according to the used bonding agent, as follows: control subgroup I, treated with Z-prime plus; subgroup II, All- Bond Universal; subgroup III, optibond; and subgroup IV, Voco-Futura bond. Surface roughness of all specimens $(\mathrm{n}=56)$ were evaluated immediately after bonding application using contact surf-test (Mitutoyo SJ 201, Japan). The composite resin (Ceram X nanohybrid) were then bonded and cured to each zirconia plate. The shear bond strength test was performed to group A with a universal testing machine at a crosshead speed of $1 \mathrm{~mm} / \mathrm{min}$ before thermocycling. Specimens of group B were thermocycled 1000 times in water between $5^{\circ} \mathrm{C}$ and $55^{\circ} \mathrm{C}$, then the shear bond strength test was performed. Bond strength values (MPa) were calculated and analyzed with a two-way ANOVA. The failure mode of each specimen was evaluated under a stereomicroscope.
\end{abstract}

Results: The mean shear bond strengths before thermocycling were $13.22,13.03,7.02$, and 6.69 (MPa) in subgroups IA, IIA, IIIA and IVA, respectively. After exposure to thermocycling the mean shear bond strengths were $13.47,11.48,0.00$ and $0.00(\mathrm{MPa})$ in subgroups IB, IIB, IIIB and IVB, respectively. The results showed that the shear bond strength were significantly higher in subgroups I and II than subgroups III and IV $(p<0.05)$. Chemical pre-treatment of zirconia with Z- Prime Plus revealed significant higher bond strength than the Optibond (subgroup III) and Voco bond (subgroup IV) before and after aging conditions.

Conclusion: Treatment with both Z-prime and All- Bond Universal resulted in higher bond strength values compared to the Optibond and Voco Futurabond. The use of Z-Prime Plus treatment in combination with air-abrasion procedure resulted in the highest bond strength value that is stable on aging.

KEYWORDS : Zirconia; bond strength; Primer; Composite; Intra-oral Repair; Bonding agents.

*Lecturer of Fixed Prosthodontics, Faculty of Dentistry, Mansoura University, Egypt

**Associate Professor of Dental Biomaterials, Faculty of Dentistry, Mansoura University, Egypt 


\section{INTRODUCTION}

Lately, more patients prefer dental restorations that syndicates high strength and good natural esthetic qualities that is why ceramic materials are replacing metallic restorations in dentistry. ${ }^{1}$ All ceramic restorations are characterized by their excellent esthetics, soft tissue biocompatibility and acceptable mechanical properties, zirconia is generally used as a single crown core material or as a fixed bridge. ${ }^{2}$

Zircon material is defined as a gem since ancient times. It is a white polymorph crystalline oxide of zirconium that is consisting of tetragonal, cubic and monoclinic phases at various ranges of temperature. The unique temperature dependent transformation from tetragonal to monoclinic phase of zirconia causes strain and a volumetric increase of 3\%-4\%. The addition of $2-3 \%$ mol yttrium oxide, partly stabilizes the tetragonal phase of zirconia (TZP) Tetragonal Zirconia Polycrystalline to prevent the propagation of cracks. This strengthening mechanism of zirconia is known as transformation toughening and it has been sometimes referred to as 'ceramic steel' due to this strengthening and toughening mechanism. ${ }^{3}$

Zirconia-based ceramics have improved mechanical resistance than other types as leucite or lithium disilicate ceramics, particularly when fixing posterior teeth. ${ }^{4}$ It was also found that zirconia is excellent in terms of mechanical performance as strength, toughness and fatigue resistance when compared to alternate materials, on the other hand, poor adhesion to substrates can be confronted in zirconia dental applications which is a problem. ${ }^{5}$

Loss of retention and chipping of veneering porcelain are the highest commonly identified clinical problems of zirconia-based ceramics. ${ }^{6}$ In many cases, poor retention and failure of restoration may be related to improper tooth preparation and unacceptable cement selection or cementation technique. ${ }^{7}$
The accurate adhesion between veneering ceramic and zirconia core is extremely vital for the success of all restorations. Previous study reported $25 \%$ fracture between zirconia core and veneering ceramic at 31 months. ${ }^{8}$ While another study detected $13 \%$ failure at 3 years. ${ }^{9}$ Fractures can occur due to; improper framework support, overloading, low fracture toughness of porcelain veneers, surface defects and fatigue. ${ }^{10-12}$

When fracture is encountered in ceramic veneers, the suitable option for solving this problem is the repair of restoration than a complete replacement. Restoration repair can be performed intraorally because this conservative method is less traumatic to the patient and more acceptable. Veneering a composite material to the zirconia framework is economic, can overcome the problem of crown removal, and reduce time consuming of lab work. Intra-oral systems for zirconia and ceramic repair have been introduced by some manufacturer. ${ }^{13}$

Numerous zirconia core surface treatments have been investigated in order to increase its surface activation for chemical adhesion and improve their bond strength with veneering ceramic or composite resin. ${ }^{14,15}$

Common surface treatment procedures for zirconia and ceramics surface treatment involves; diamond bur abrasion, grinding, sandblasting with $\mathrm{Al}_{2} \mathrm{O}_{3}$, laser-treatment, acid-etching, silane application, or the usage of more than one procedure. ${ }^{5}$ The most clinically recommended surface treatment for increasing surface roughness and mechanical interlocking to zirconia, is $\mathrm{Al}_{2} \mathrm{O}_{3}$ abrasion. ${ }^{16,17} \mathrm{Air}$ abrasion is used to enlarge surface area, increase surface energy, improve wettability and adhesion of zirconia-based ceramics. Many studies have shown that comparable surface roughness patterns can be produced with aluminum oxide abrasion and silica coating processes. Air abrasion displays a critical role in phase transformation of tetragonal to monoclinic phase that increases flexural strength. ${ }^{18,19}$ 
Chemical pretreatment methods are still being investigated, a study showed some micromorphologic changes on the surface topography of zirconia after applying $9.5 \%$ hydrofluoric acid (HF) in $25^{\circ} \mathrm{C}$ for $24 \mathrm{~h}, 9.5 \% \mathrm{HF}$ in $80^{\circ} \mathrm{C}$, and $48 \%$ $\mathrm{HF}$ in $25^{\circ} \mathrm{C}$ and concluded that concentration and temperature of acid could affect the reaction rate. ${ }^{20}$

Another convenient method used for activation of zirconia ceramic surfaces is the application of different primers that has reasonable cost and simplified application. Primers that have the composition of 10-methacryloxydecyl dihydrogen phosphate (MDP) and phosphate monomers can improve the bond strength to zirconia. ${ }^{21-23}$ Many researches ${ }^{21,24-26}$ reported that the combined use of MPD primer and air-abrasion can improve the bond strength to zirconia core. The air abrasion was found to improve resin bonding to zirconia mechanically, while the adhesive monomers are necessary for chemical bonding. ${ }^{27}$

Many studies concluded that these primers bonding agents not only can form a favorable bond with tooth structures, but also they can bond to other different substrates such as resins, metals and other indirect restorations, including zirconia ceramics and lithium disilicate. ${ }^{28-30}$

Before performing clinical studies, in-vitro studies should be undertaken to prove materials' applicability and performance, however in-vitro studies should replicate clinical conditions, ${ }^{31}$ therefore thermal-cycling and long term water storage are important factors during in-vitro studies. ${ }^{32,33}$

Bond strength measurement is used to assess the efficacy of an adhesive system and to subsequently predict its clinical implementation. There are two types of bond strength tests that are most commonly used; tensile and shear bond strength. Several researches have described that cohesive fractures are more frequently occurring with shear bond strength rather than adhesive fractures. ${ }^{34}$ In clinical situations, cohesive failures are hardly detected in bonded restorations.

This research assessed the thermal-cycling effect on the shear bond-strength of composite resins as repair material to zirconia substrate using different bonding agents as a method for chemical activation of inert zirconia surface. The null hypothesis was that, there would be no significant difference in the shear bond strength values among the various groups tested.

\section{MATERIALS AND METHODS}

Materials used in the study and their composition are shown in Table 1.

For this in-vitro study, fifty six plates of zirconia (10 $\mathrm{mm}$ in length X $2 \mathrm{~mm}$ in thickness) were produced using CAD/CAM technology (Arum x5 400, Doowon Co., Ltd. Daejeon, South Korea). Specimens are then sintered at $1550^{\circ} \mathrm{C}$ according to a cycle recommended by the manufacturer in a sintering furnace (Luoyang, China). All specimens were air abraded using $50 \mu \mathrm{m} \mathrm{Al}_{2} \mathrm{O}_{3}$ particles at low pressure 2 bar ${ }^{35}$ for 10 seconds, using a sandblasting apparatus (JNBP-2, Jianian Futong Medical Equipment Co. Ltd., Tianjin, China) followed by rinsing for 60 minutes with distilled water in an ultrasonic cleaner device (MCS, CD4820, Codyson, China) and drying with an air syringe. All specimens were divided into two equal groups $(n=28)$ group A without thermocycling and group B with thermocycling. Each group was subdivided into four subgroups $(n=7)$ according to the used bonding technique; control subgroup I, treated with Z-prime plus; subgroup II, All- Bond Universal; subgroup III, Optibond; and subgroup IV, Voco-Futura bond. 
TABLE (1) Materials utilized in this study

\begin{tabular}{|c|c|c|c|}
\hline Material & Batch No & Composition & Manufacturer \\
\hline Zirconia ceramic & 5054089 & Zirconium dioxide $\mathrm{ZrO}_{2} 3 \mathrm{Y}$-TZP-A or $3 \mathrm{Y}$-TZP & $\begin{array}{lr}\text { Nacera, } & \text { Doceram } \\
\text { medical ceramic Gmbh- } & \text { 65-67, } \\
\text { Hesslingsweg } & \text { Dortmund, } \\
\text { D-44309 } & \\
\text { Germany } & \end{array}$ \\
\hline Z-Prime Plus & 1800001455 & $\begin{array}{l}\text { BPDM, Ethanol } 75-85 \% \text {, HEMA 5-10\%, Bis-GMA } \\
5-10 \% \text {, MDP } 1-5 \% \text {, Proprietary (phosphate and } \\
\text { carboxylate functional monomer) }\end{array}$ & $\begin{array}{l}\text { Bisco Inc., Schaumburg, } \\
\text { IL 60193,USA }\end{array}$ \\
\hline All-Bond Universal & 1800004472 & $\begin{array}{l}\text { BPDM, Ethanol 30-50\%, HEMA 5-25\%, Bis-GMA } \\
20-50 \% \text {, MDP 5-25\%, water, initiator }\end{array}$ & $\begin{array}{l}\text { Bisco Inc., Schaumburg, } \\
\text { IL 60193, USA }\end{array}$ \\
\hline $\begin{array}{l}\text { Kerr, OptiBond ALL-IN- } \\
\text { ONE. Self-Etch Dental } \\
\text { Adhesive }\end{array}$ & 6494038 & $\begin{array}{l}\text { Monomers } \\
\text { - GPDM Self-etching adhesive monomer } \\
\text { - Comonomers including mono- and difunctional } \\
\text { methacrylate monomers } \\
\text { - Solvents water, acetone and ethanol } \\
\text {-Photo-initiator (CQ)-based photoinitiator system } \\
\text { - Fillers three nano-sized fillers } \\
\text { - Fluoride-releasing fillers - sodium hexafluorosilicate } \\
\text { and ytterbium fluoride }\end{array}$ & $\begin{array}{l}\text { Kerr Itaia Sri, Via } \\
\text { Passanti, 332, Italy }\end{array}$ \\
\hline VOCO Futura-bond DC & 1742689 & Acidic adhesive monomer, 2-hydroxyethyl methacrylate & Voco, America, Inc \\
\hline $\begin{array}{l}\text { Ceram.X Sphere TEC } \\
\text { TM One Nano hybrid } \\
\text { composite, Dentsply }\end{array}$ & 1801000949 & $\begin{array}{l}\text { Non-agglomerated barium glass fillers and ytterbium } \\
\text { fluoride }(\approx 0.6 \mu \mathrm{m}) \text {, highly dispersed, methacrylic } \\
\text { polysiloxane nano-particles. }\end{array}$ & $\begin{array}{l}\text { EENTSPLY Detrey } \\
\text { GmbH, Germany }\end{array}$ \\
\hline
\end{tabular}

\section{Specimens preparation}

Subgroup I (ZP) Control group, specimens were treated with Z-Prime Plus (Bisco, USA) primer according to manufacture recommendation by applying 1-2 coats of Z-Prime plus to zirconia surface, and then drying for 3-5 s with an air syringe.

Subgroup II (AB), specimens were treated with light-cured dental adhesive All-Bond Universal (Bisco, USA) primer as follows: 2 drops of AllBond Universal were dispensed into a clean well, 1 coat was applied to zirconia surface and air dried to get rid of excess solvent, then light cured for $10 \mathrm{~s}$.

Subgroup III (OB), specimens were treated with self-etching adhesive OptiBond All-InOne (Kerr, Italia) to zirconia surface according to manufacturer's recommendations as follows: 2-3 drops of OptiBond All-In-One adhesive were dispensed into a clean well. A disposable applicator brush was used to apply adhesive to zirconia surface. Two coats of OptiBond were applied with a brushing motion for $20 \mathrm{~s}$ each. The adhesive was dried with gentle air for $5 \mathrm{~s}$, then light cured for $10 \mathrm{~s}$.

Subgroup IV (VB), specimens were treated with dual-cure universal adhesive VOCO- Futurabond (Voco, America, Inc.) a coat was applied and air dried for $5 \mathrm{~s}$ then light cured for $10 \mathrm{~s}$.

\section{Surface roughness measurements}

Surface roughness of all specimens $(n=56)$ were evaluated immediately after bonding application using contact surf-test. The average surface roughness 
(Ra) of each group was examined using a profilometer (Surftest SJ210, Mitutoyo Corp., Kawasaki, Japan) according to the ISO 4287-1997. For this purpose, seven specimens were measured of each group and the stylus was placed in the middle of the specimen surface. Each specimen was scanned 5 times and the mean roughness parameter (Ra) was calculated in $(\mu \mathrm{m})$. The tracing length was $8 \mathrm{~mm}$, at a scanning speed $0.5 \mathrm{~mm} / \mathrm{s}$. The resolution of the recorded data was $0.01 \mu \mathrm{m}$.

\section{Shear bond strength measurements}

A custom- made Teflon split mold with $6 \mathrm{~mm}$ diameter and $4 \mathrm{~mm}$ thickness, was centralized on the zirconia surface. The composite resin (Ceram X Nano hybrid, Dentsply) was dispensed, inserted into the mold, condensed and light cured according to manufacturer's recommendation.

The bond-strength test (SBS) was performed on a universal testing machine (Instron Universal testing machine, model no. 3345, England) at a crosshead speed of $0.5 \mathrm{~mm} / \mathrm{min}$, data was presented using Computer software BlueHill Instron.

A knife edge chisel apparatus (5 mm blade length) was used to direct a parallel shearing load exactly at the composite resin/zirconia interface. Specimens of group B $(n=28)$ were thermocycled 1000 times in water between $5^{\circ} \mathrm{C}$ and $55^{\circ} \mathrm{C}$, water storage. The dwell time at each temperature was 30 seconds with a transfer time of 15 seconds between baths (Theromocycler, Robota, Alexandria, Egypt). The thermocycling conditions were based on the calculation of that 1000 thermocycles would simulate the situation during one year in the oral cavity. ${ }^{37}$ After thermocycling, specimens were tempered to room temperature in a water bath then shear bond strength test was performed. SBS values were recorded in mega-Pascal (MPa).

The debonded zirconia specimens were carefully examined for failure modes (adhesive, cohesive or mixed) under a stereomicroscope (BS-3060C, China) at magnification of $x 40$. The failure modes are classified as cohesive failure; that is referred to a complete fracture within the ceramic or within the composite resin, adhesive failure; which means fracture between the ceramic (or composite resin) and bonding agent, and mixed fracture; which indicates fracture involving two materials.

\section{Statistical analysis}

The collected data were studied using one way and 2-way ANOVA (Analysis of Variance test), when significant differences were found between the groups, Bonferroni test (post-hoc test) was applied. The level of significance was set at $\mathrm{p}$-value $<0.05$.

\section{RESULTS}

Surface roughness were evaluated immediately after bonding application using contact surf-test device The resultant average surface roughness values ( $\mathrm{Ra}$ ) expressed in $\mu \mathrm{m}$ were recorded and tabulated in Table 2. It was found that, $\mathrm{Z}$ prime subgroup showed a high statistical significant mean roughness value $(2.010 \mu \mathrm{m})$ among all groups $\mathrm{p}=0.000$. Optibond subgroup showed a statistical significant mean roughness value among all groups $(1.088 \mu \mathrm{m})$, except with Voco-Futurabond $\mathrm{p}=0.188$. Voco-futurabond showed a statistical nonsignificant mean roughness value $(0.738 \mu \mathrm{m})$ with all groups, except with $\mathrm{Z}$ prime where $\mathrm{p}=0.000$. AllBond Universal showed a statistical non-significant mean roughness value $(0.689 \mu \mathrm{m})$ with all groups, except with $\mathrm{Z}$ prime subgroup where $\mathrm{p}=0.000$ and Optibond where $\mathrm{p}=0.011$.

Means and standard deviations for shear bond strength (MPa) for all tested subgroups were recorded before and after thermocycling then tabulated as in Table 3. Two-way ANOVA showed that the shear bond strength were significantly higher in subgroups I and II compared to the other two subgroups $(\mathrm{p}<0.05)$. Chemical pre-treatment of zirconia with Z- Prime Plus revealed significantly higher bond strength than the optibond (subgroup III) and Voco bond (subgroup IV) before and after aging. 
The current results also revealed that there were no significant difference between the mean shear bond strength of subgroup IA (Z-prime) and subgroup IIA (All-bond universal) before thermocycling, the same results were observed between subgroup III (Optibond) and subgroup IV (Voco-Futura bond). There were no significant difference in subgroup II before and after thermocycling. There were no significant difference between subgroup IIIB and IVB after aging. However it was found that, there were high significant difference in the mean and standard deviations of shear bond strength values before and after thermocycling in both subgroup III and IV.

In the present study, it was noticed that specimens with lower bond strength failed adhesively; at zirconia-composite resin interface. On the other hand, specimens with higher bond strength showed mixed failure modes.

TABLE (2) Showing the average of surface roughness values (Ra) expressed in Micrometer ( $\mu \mathrm{m})$ using one way ANOVA and post hoc test.

\begin{tabular}{|c|c|c|c|c|c|c|c|}
\hline & $\begin{array}{c}\text { Non-sintered } \\
\text { Group }\end{array}$ & $\begin{array}{c}\text { Sintered } \\
\text { Group }\end{array}$ & $\begin{array}{c}\text { Sandblasted } \\
\text { Group }\end{array}$ & $\begin{array}{c}\text { Z-Prime } \\
\text { Subgroup I }\end{array}$ & $\begin{array}{c}\text { All-bond } \\
\text { Universal } \\
\text { Subgroup II }\end{array}$ & $\begin{array}{c}\text { Optibond } \\
\text { Subgroup III }\end{array}$ & $\begin{array}{c}\text { Voco-Futrabond } \\
\text { Subgroup IV }\end{array}$ \\
\hline $\begin{array}{c}\text { Roughness in } \\
(\mu \mathrm{m}) \pm(\mathrm{SD})\end{array}$ & $\begin{array}{c}0.414^{\mathrm{cd}} \pm \\
(0.124)\end{array}$ & $\begin{array}{c}0.449^{\mathrm{cd}} \pm \\
(0.049)\end{array}$ & $\begin{array}{c}0.614^{\mathrm{cd}} \pm \\
(0.039)\end{array}$ & $\begin{array}{c}2.010^{\mathrm{a}} \pm \\
(0.555)\end{array}$ & $\begin{array}{c}0.689^{\mathrm{cd}} \pm \\
(0.158)\end{array}$ & $\begin{array}{c}1.088^{\mathrm{bc}} \pm \\
(0.290)\end{array}$ & $\begin{array}{c}0.738^{\mathrm{bcd}} \pm \\
(0.126)\end{array}$ \\
\hline$($ Min-max $)$ & $0.271-0.650$ & $0.395-0.531$ & $0.544-0.693$ & $0.916-2.756$ & $0.463-0.958$ & $0.638-.1 .590$ & $0.521-0.980$ \\
\hline $\begin{array}{c}95 \% \text { Confidence } \\
\text { interval for mean }\end{array}$ & $0.325-0.503$ & $0.413-0.484$ & $0.597-0.631$ & $1.703-2.318$ & $0.615-0.763$ & $0.921-1.256$ & $0.679-0.797$ \\
\hline
\end{tabular}

Similar superscripted letters denotes statistical non-significant at $p=0.05$

TABLE (3) Showing means and standard deviations of shear bond strength of the different study groups before and after thermocycling using Two Way ANOVA

\begin{tabular}{|c|c|c|c|c|c|}
\hline & No. & Z-prime & All Bond Universal & Optibond & Voco-Futurabond \\
\hline Before thermocycling Group A & 28 & $13.22^{\mathrm{a}}(0.45)$ & $13.03^{\mathrm{a}}(1.66)$ & $7.02^{\mathrm{ab}}(1.56)$ & $6.69^{\mathrm{ab}}(1.69)$ \\
\hline After thermocycling Group B & 28 & $13.47^{\mathrm{a}}(3.77)$ & $11.48^{\mathrm{a}}(1.24)$ & $0.00^{\mathrm{b}}$ & $0.00^{\mathrm{b}}$ \\
\hline
\end{tabular}

Similar superscripted small letters denote statistically non-significant difference at $p=0.05$

\section{DISCUSSION}

This study appraised the effect of aging on the shear bond strength (SBS) between zirconia core and Nano hybrid composite resin as a repair material using different bonding agents.

Clinical studies of yttrium-stabilized tetragonal zirconia polycrystalline (Y-TZP) ceramic restorations showed that the common causes of failure were chipping and delamination of veneering ceramic..$^{37,38}$ These failures can be a serious impediment for patients and clinicians. The veneers chipping can occur due to an inadequate micro-mechanical interlocking with a deficiency of chemical bonding at the interface and tensile stress on the surface of the veneer. ${ }^{39,40}$ The bonding 
between ceramic veneers and zirconia core was found to be weakest feature of the restoration. ${ }^{41} \mathrm{~A}$ reasonable micromechanical interlocking at the interface of zirconia core and its veneer, attained by increasing surface roughness, can improve their bond strength. ${ }^{42}$ Surface treatments to YSZ substrate can improve bond strength with veneer ceramic and can be done by adding or removing materials from the surface. Chipping has many proposed repair techniques, but the direct repair of this kind of failure is significant ${ }^{43}$, many repair systems utilizes a resin composite materials. ${ }^{44}$ After veneer chipping, when the framework is bared, bonding between the composite resin repair material and zirconia core must be done successfully. ${ }^{45}$

The use of CAD/CAM technology system for soft machining zirconia blocks in our study is chosen to minimize the volumetric changes of zirconia. ${ }^{46} \mathrm{In}$ the current study, the new nano-hybrid composite (Ceram.x, Sphere TEC ${ }^{\text {TM }}$ ) was chosen because of its high filler load that supports mechanical strength and reduces polymerization shrinkage. Maximization of filler load was able to be done by using new type of pre-polymerized filler primary particles (Sphere TEC) which are smaller than $1 \mu \mathrm{m}$. The SphereTEC fillers are virtually perfectly spherical and have a distinct, micro-structured surface that reduces the amount of resin needed in ceram.x and thus the stickiness of the paste to hand instruments. Submicron SphereTEC particles resulted in msuperior esthetics and wear resistance, as during finishing and polishing, the fillers are removed layer-bylayer leading to an even restoration surface after polishing. ${ }^{47}$

The results of this study rejected the null hypothesis, since various groups tested produced significantly different SBS values. Mechanical and chemical surface treatments methods have been utilized to increase bond strength between ceramic core material and resin composite. All tested groups were mechanically treated using an $\mathrm{Al}_{2} \mathrm{O}_{3}$ abrasion procedure, as this mechanical surface treatment improves bond strength between the resin and zirconia by increasing surface area, surface roughness and wettability, thus resulting in improving of resin flow onto the zirconia surfaces. ${ }^{24,48}$ In addition, this procedure removes organic contaminants from the zirconia surface for chemical bonding. ${ }^{27}$ Other researches have reported that air-abrasion process can produce micro-cracks in zirconia surface that can result deteriorating zirconia properties; ${ }^{24,49}$ therefore, the zirconia in this current study were abraded at a low pressure of 2 bar, using a powder with a particle size of $50 \mu \mathrm{m}$ $\mathrm{Al}_{2} \mathrm{O}_{3}$ to avoid surface damage. ${ }^{49,50}$

Results of some previous studies, showed that one of the most commonly used tests for evaluation of the bond strength is the shear bond strength test. $^{27,51}$

In this study 1000 thermocycles were performed to simulate intra-oral environmental aging conditions. Group III and IV showed failure and separation of composite resin from zirconia after thermocycling occurred, this can be due to the effect of thermal stresses that might have decline the zirconia-composite resin bond because of the difference in the coefficient of thermal expansion and bond deterioration via hydrolysis. ${ }^{52}$ Specimens preparation with machining technique for tensile bond strength testing can cause adhesive defects and resulted in stress-concentration at the zirconia interface and affect the bond strength values ${ }^{49,53}$ but the shear test is more simple and does not require samples trimming; yet, the shear bond strength test has been questioned for nonhomogeneous stress distribution at the interface. ${ }^{53}$

Many research works found that the preeminent adhesion to zirconia ceramic can be acquired by exploiting primers containing a phosphate-based functional monomer, especially MDP; $23,25,49,51$ hence in this study, two types of the primers were used that contained MDP monomer, and it seems that they are both equally effective regarding aged bond-strength. According to the results of this study, both Z-Prime Plus and All-Bond Universal 
primers have higher bond strength that does not deteriorate with aging, other than Optibond and Voco-Futurabond that have significantly lower bond strength that deteriorates after aging.

Z-Prime Plus treatment group showed a high statistical significant mean roughness value $(2.010$ $\mu \mathrm{m}$ ) among all subgroups $\mathrm{p}=0.000$, this might be accredited to the large molecular size and nature of this material; as it chemically bonds to zirconia structure and its way of application; as it requires two coats. Z-Prime Plus group has also significantly higher bond strength values because of its chemical structure that contains conventional MDP and carboxylic monomers which can chemically react with the zirconia oxide layer at the interface. ${ }^{54}$ The interfacial forces might improve the wettability and chemical bonding to zirconia ceramics. ${ }^{24,54} \mathrm{In}$ addition, MDP has an amphiphilic construction; the vinyl group, as the hydrophobic end, can copolymerize with the resin monomer and the phosphate group as the hydrophilic end can interact with the hydroxyl groups on the zirconia surface, improving the chemical affinity. ${ }^{21,55}$ It seems that the synergistic effect between acidic MDP and carboxylic monomer is the most likely reason for having the maximum bond strength values. ${ }^{29}$ The results of this current study were in accordance with Zandparsa et al. ${ }^{23}$ and Shin et al. ${ }^{25}$ who reported that the combined use of Z-Prime Plus primer and air abrasion improved the bond strength of zirconia ceramic to resin cements. It was also noted that Z-prime Plus group has a higher shear bond strength after thermocycling, although non-significant, than before thermocyling, this might happened due to an improved polymerization process in the Z-prime that occurred by thermal stresses of thermocyling.

In this study, All-Bond Universal group showed a high shear bond strength value that does not significantly differ than Z-prime group, although it has statically significant lower roughness value than Z-prime group, the similarity of bond strength value might be attributed to the higher percentage of MDP in All-Bond (5-25\%) as compared to Z-prime
(1-5\%), MDP. This higher concentration may have intensified the chemical bonding between composite and zirconia surface in the All Bond Universal group, and stabilized it over thermocycling and aging conditions. On the other hand, Optibond subgroup showed a statistical significant mean roughness value among all subgroups $(1.088 \mu \mathrm{m})$, except with Voco-Futurabond $\mathrm{p}=0.18$. However, the both subgroups showed a significantly lower bond strength value as they do not contain MDP in their composition for chemical bond formation with composite resin.

In this study, it was observed that specimens with lower bond strength failed adhesively; at zirconiacomposite resin interface as in Optibond and Voco bond specimens. On the other hand, specimens with higher bond strength values due to primer treatments, mixed failure modes were observed as in Z-prime and All-bond universal specimens. These results were in agreement with the studies of Seabra et al., (2014) ${ }^{29}$ and Xie et al., (2016). ${ }^{30}$ Cohesive failures within the zirconia specimens did not occur, which is one of the most important advantages for zirconia restorations because the intraoral repair of zirconia restorations is difficult and adequate bond cannot be achieved to repair zirconia with composite resin. ${ }^{30}$

\section{CONCLUSION}

Under the limits of the current study, it could be concluded that, the bond strength between zirconia core and Ceram-x composite resin was affected by the chemical surface treatment. Treatment with both primers (Z-Prime Plus and All-Bond Universal) resulted in higher more stable bond strength than the other two bonding agents (Optibond and VocoFutrabond). Treating the chipped zirconia surface by either Z-Prime Plus or All-Bond Universal after $\mathrm{Al}_{2} \mathrm{O}_{3}$-abrasion process can enhance composite resin adhesion to zirconia ceramic as it resulted in a higher bond strength that is not prone to aging. 


\section{REFERENCES}

1. Cavalcanti AN, Foxton RM, Watsn TF, et al: Bond strength of resin cements to a zirconia ceramic with different surface treatments. Oper Dent 2009; 34:280-287.

2. Koutayas SO, Vagkopoulou T, Pelekanos S Koidis P, Strub JR. Zirconia in dentistry: part 2. Evidence-based clinical breakthrough. Eur J Esthet Dent. 2009; 4:348-380.

3. Kelly JR, Denry I. Stabilized zirconia as a structural ceramic: An overview. Dent Mater. 2008; 24:289-298.

4. Ozkurt Z, Kazazoglu E. Clinical success of zirconia in dental applications. J Prosthodont, 2010. 19(1): p. 64-72.

5. Blatz MB, Sadan A, Kern M. Resin-ceramic bonding: a review of the literature. J Prosthet Dent, 2003. 89(3): p. 268-274.

6. Roediger M, Nikolaus G, Alfons H, Sven R. Prospective evaluation of zirconia posterior fixed partial dentures: four-year clinical results. Int J Prosthodont, 2010; 23: 141149 .

7. Beuer F, Daniel E, Wolfgang G, John AS. Three-year clinical prospective evaluation of zirconia-based posterior fixed dental prostheses (FDPs). Clin Oral Investig, 2009; 13: 445-451

8. Raigrodski AJ, Chiche GJ, Potiket N, et al. The efficacy of posterior three-unit zirconium-oxide-based ceramic fixed partial dental prostheses: a prospective clinical pilot study. J Prosthet Dent, 2006; 96:237-244.

9. Sailer I, Feher A, Filser F, et al. Prospective clinical study of zirconia posterior fixed partial dentures: 3-year followup. Quintess Int. 2006; 37:685-693.

10. Marchack BW, Futatsuki Y, Marchack CB, White SN. Customization of milled zirconia copings for all-ceramic crowns: a clinical report. J Prosthet Dent 2008; 99:169-173.

11. Beuer F, Schweiger J, Eichberger M, Kappert HF, et al. High-strength CAD/CAM-fabricated veneering material sintered to zirconia copings-a new fabrication mode for all-ceramic restorations. Dent Mater. 2009; 25:121-128.

12. Coelho PG, Silva NR, Bonfante EA, Guess PC, et al. Fatigue testing of two porcelain-zirconia all-ceramic crown systems. Dent Mater. 2009; 25:1122-1127.

13. Blum IR, Lynch CD, Wilson NH. Teaching of direct composite restoration repair in undergraduate dental schools in the United Kingdom and Ireland. Eur J Dent Educ. 2012; 6:53-58.
14. Della Bona A, Borba M, Benetti P, Cecchetti D. Effect of surface treatments on the bond strength of a zirconia-reinforced ceramic to composite resin. Braz Oral Res 2007; 21:10-15.

15. Xible AA, de Jesus Tavarez RR, de Araujo Cdos R, Bonachela WC. Effect of silica coating and silanization on flexural and composite-resin bond strengths of zirconia posts: an in vitro study. J Prosthet Dent. 2006; 95:224-229.

16. Kern M, Barloi A, Yang B: Surface conditioning influences zirconia ceramic bonding. J Dent Res 2009; 88:817-822.

17. Zhang Y, Lawn BR, Rekow ED, et al: Effect of sandblasting on the long-term performance of dental ceramics. J Biomed Mater Res B Appl Biomater 2004; 71:381-386.

18. Magne P, Paranhos MPG, Burnett LH. New zirconia primer improves bond strength of resin-based cements. Dent Mater. 2010; 26:345-352.

19. Hallmann L, Ulmer P, Lehmann F, Wille S, Polonskyi O, Johannes M, et al. Effect of surface modifications on the bond strength of zirconia ceramic with resin cement resin. Dent Mater. 2016; 32:631-639.

20. Sriamporn T, Thamrongananskul N, Busabok C, Poolthong S, Uo M, Tagami J. Dental zirconia can be etched by hydrofluoric acid. Dent Mater J. 2014; 33:79-85.

21. Ahn JS, Yi YA, Lee Y, Seo DG. Shear Bond Strength of MDP-Containing Self-Adhesive Resin Cement and YTZP Ceramics: Effect of Phosphate Monomer-Containing Primers. Biomed Res Int. 2015; 2015:1-7.

22. Komine F, Fushiki R, Koizuka M, Taguchi K, Kamio S, Matsumura H. Effect of surface treatment on bond strength between an indirectcomposite material and a zirconia framework. J Oral Sci. 2012; 54: 39-46.

23. Zandparsa R, Talua NA, Finkelman MD, Schaus SE. An in vitro comparison of shear bond strength of zirconia to enamel using different surface treatments. J Prosthodont. 2014; 23: 117-123.

24. Tanış MÇ, Akay C, Karakış D. Resin cementation of zirconia ceramics with different bonding agents. Biotechnol Biotechnol Equip. 2015; 29: 363-367.

25. Shin YJ, Shin Y, Yi YA, Kim J, Lee IB, Cho BH, et al. Evaluation of the shear bond strength of resin cement to YTZP ceramic after different surface treatments. Scanning. 2014; 36: 479-486. 
26. Wang C, Niu LN, Wang YJ, Jiao K, Liu Y, Zhou W, et al. Bonding of resin cement to zirconia with high presure primer coating. PLoS One. 2014; 9: e101174.

27. Tzanakakis EG, Tzoutzas IG, Koidis PT. Is there a potential for durable adhesion to zirconia restorations? A systematic review. J Prosthet Dent. 2016; 115: 9-19.

28. Yoshida F, Tsujimoto A, Ishii R, Nojiri K, Takamizawa T, Miyazaki M, et al. Influence of surface treatment of contaminated lithium disilicate and leucite glass ceramics on surface free energy and bond strength of universal adhesives. Dent Mater J. 2015; 34: 855-862.

29. Seabra B, Arantes-Oliveira S, Portugal J. Influence of multimode universal adhesives and zirconia primer application techniques on zirconia repair. J Prosthet Dent. 2014; 112: 182-187.

30. Xie H, Li Q, Zhang F, Lu Y, Tay FR, Qian M, et al. Comparison of resin bonding improvements to zirconia between one-bottle universal adhesives and tribochemical silica coating, which is better? Dent Mater. 2016; 32: 403-411.

31. Barclay CW, Boyleoyle EL, Williams R, Marquisp M. The effect of thermocycling on five adhesive luting cements. J Oral Rehabil 2002; 29:546-552.

32. Attia A. Influence of treatment modalities of prepared teeth on retention of cast metal copings bonded with self-adhesive resin cements. Quintessence Int. 2012; 43: (6):e73-81

33. Shahin R, Kern M. Effect of air-abrasion on the retention of zirconia ceramic crowns luted with different cements before and after artificial aging. Dent Mater 2010; 26:922928.

34. Della Bona A, Northeast SE: Shear bond strength of resin bonded ceramic after different try-in procedures. J Dent 1994; 22:103-107.

35. Guarda GB, Correr AB, Gonçalves LS, Costa AR, Bor-ges GA, Sinhoreti MA, et al. Effects of surface treatments, thermocycling, and cyclic loading on the bond strength of a resin cement bonded to a lithium disilicate glass ceramic. Oper Dent. 2013; 38: 208-217.

36. Fischer J, Grohmann P, Stwawrczyk B. Effect of zirconia surface treatments on the shear bond strength of zirconia/ veneering ceramic composite. Dent Mater J. 2008; 27:448-454.

37. Sailer I, Gottnerb J, Kanelb S, Hammerle CH. Randomized controlled clinical trial of zirconia-ceramic and metalceramic posterior fixed dental prostheses: a 3-year followup, Int.J. Prosthodont. 2009; 22:553.
38. Wolfart S, Harder S, Eschbach S, Lehmann F, Kern M. Four-year clinical results of fixed dental prostheses with zirconia substructures (Cercon): end abutments vs. cantilever design, Eur. J. Oral Sci. 2009; 117: 741-749.

39. Kosmač T Oblak Č Marion L.The effects of dental grinding and sandblasting on ageing and fatigue behavior of dental zirconia (Y-TZP) ceramics, J. Eur. Ceram. Soc. 2008; 28:1085- 1090 .

40. Tholey MJ, Berthold C, Swain MV, Thiel N. XRD 2 micro-diffraction analysis of the interface between Y-TZP and veneering porcelain: role of application methods, Dent. Mater. 2010; 26: 545-552.

41. Ozkurt Z, Kazazoglu E, Unal A. In vitro evaluation of shear bond strength of veneering ceramics to zirconia, Dent. Mater. J.2010; 29: 138-146.

42. Casucci A, Mazzitelli C, Monticelli F, Toledano M, Osorio R, Osorio E, Papacchini F, Ferrari M. Morphological analysis of three zirconium oxide ceramics: effect of surface treatments, Dent. Mater.2010; 26: 751-760.

43. Cristoforides P, Amaral R, May LG, Bottino MA, Valandro LF. Composite resin to yttria stabilized tetragonal zirconia polycrystal bonding: comparison of repair methods. Oper Dent. 2012; 37:263-271.

44. Attia A. Influence of surface treatment and cyclic loading on the durability of repaired all-ceramic crowns. J Appl Oral Sci. 2010; 18:194-200.

45. Goia TS, Leite FP, Valandro LF, Ozcan M, Bottino MA.. Repair bond strength of a resin composite to alumina reinforced feldspathic ceramic. Int J Prosthodont. 2006; 19:400-402.

46. Cho JH, Kim SJ, Shim JS, Lee KW. Effect of zirconia surface treatment using nitric acid-hydrofluoric acid on the shear bond strengths of resin cements. J Adv Prosthodont. 2017; 9: 77-84.

47. Catalogue of Dentsupply Company. Website: www.dentsply-spheretec.com

48. Kim RJ, Woo JS, Lee IB, Yi YA, Hwang JY, Seo DG. Performance of universal adhesives on bonding to leucite- reinforced ceramic. Biomater Res. 2015; 19: 11 .

49. Inokoshi M, Poitevin A, De Munck J, Minakuchi S, Van Meerbeek B. Bonding effectiveness to different chemically pre-treated dental zirconia. Clin Oral Investig. 2014; 18: 1803-1812. 
50. Su N, Yue L, Liao Y, Liu W, Zhang H, Li X, et al. The effect of various sandblasting conditions on surface changes of dental zirconia and shear bond strength be-tween zirconia core and indirect composite resin. J Adv Prosthodont. 2015; 7 : 214-223.

51. Kim JH, Chae SY, Lee Y, Han GJ, Cho BH. Effects of multipurpose, universal adhesives on resin bonding to zirconia ceramic. Oper Dent. 2015; 40: 55-62.

52. Yoo JY, Yoon HI, Park JM, Park EJ .Porcelain repair Influence of different systems and surface treatments on resin bond strength. J Adv Prosthodont 2015; 7:343-351.

53. Panah FG, Rezai SM, Ahmadian L. The influence of ceramic surface treatments on the micro-shear bond-strength of composite resin to IPS Empress 2. J Pros-thodont. 2008; 17: 409-414.

54. Yi YA, Ahn JS, Park YJ, Jun SH, Lee IB, Cho BH, et al. The effect of sandblasting and different primers on shear bond strength between yttria-tetragonal zirconia poly-crystal ceramic and a self-adhesive resin cement. Oper Dent. 2015; 40: 63-71.

55. Román-Rodríguez JL, Fons-Font A, Amigó-Borrás V, Granell-Ruiz M, Busquets-Mataix D, Panadero RA, et al. Bond strength of selected composite resin-cements to zir-conium-oxide ceramic. Med Oral Patol Oral Cir Bucal. 2013; 18: e115-e123. 